\title{
Computational Fluid Dynamics for Cerebral Aneurysms in Clinical Settings
}

\author{
Fujimaro Ishida, Masanori Tsuji, Satoru Tanioka, \\ Katsuhiro Tanaka, Shinichi Yoshimura, \\ and Hidenori Suzuki
}

\section{Introduction}

Computational fluid dynamics (CFD) is a computational science which connects experiment and theory. Therefore, it is important to understand the need of validation and verification of CFD for cerebral aneurysms when the hemodynamic results are applied to surgical decision-making in clinical settings.

CFD for a cerebral aneurysm using the patient-specific geometry model was first reported by DA Steinman et al. in 2003 [1], and it has been revealing that hemodynamics contributes to understanding aneurysm pathology including initiation, growth, and rupture [2-10]. On the other hand, CFD has not permeated into a clinical setting of cerebral aneurysms due to several limitations including analysis time and complicated process. Therefore, we present our practical application of CFD for the treatment planning of cerebral aneurysms.

\section{CFD Process for Cerebral Aneurysms}

The CFD process for cerebral aneurysms is the following [2, $11,12]$ : the digital imaging and communication in medicine (DICOM) datasets of 3D CT angiography and 3D rotational angiography are loaded into Mimics Innovation Suite

F. Ishida $(\bowtie) \cdot$ M. Tsuji $\cdot$ S. Tanioka $\cdot$ K. Tanaka

Department of Neurosurgery, Mie Chuo Medical Center, NHO,

Tsu, Japan

e-mail: satoru-tanioka@umin.net

S. Yoshimura

Department of Neurosurgery, Hyogo College of Medicine,

Hyogo, Japan

H. Suzuki

Department of Neurosurgery, Mie University Graduate School of Medicine, Tsu, Mie, Japan
(Materialise Japan, Kanagawa, Japan) to extract aneurysm geometry as stereolithography (STL). The STL file is integrated into 3-matic (Materialise Japan, Kanagawa, Japan) and geometry in the region of interest is segmented. In addition, the geometry is remeshed by a triangle measuring $0.25 \mathrm{~mm}$ at the maximum length for correction of a distortion comprising the STL. The fluid domain is meshed using ANSYS ICEM CFD (ANSYS Inc. Canonsburg, Pennsylvania) to create tetrahedral elements that are established as $0.6 \mathrm{~mm}$ at maximum and $0.1 \mathrm{~mm}$ at minimum using the Octree's method. On the geometry surface, six prism layers are added with total heights of $0.148 \mathrm{~mm}$. The inlet is prolonged vertically at the surface to establish fully developed laminar flow according to Poiseuille's law.

Numerical modeling is performed using ANSYS CFX (ANSYS Inc. Canonsburg, Pennsylvania). For the fluid domain, 3D laminar flow fields are obtained by solving the continuity and Navier-Stokes equations, and discretization is made by the finite volume method. Blood is assumed to be an incompressible Newtonian fluid with a density of $1056 \mathrm{~kg} /$ $\mathrm{m}^{3}$ and a viscosity of $0.0035 \mathrm{~Pa}$ s. Typical flow waveform of phase-contrast MR imaging is scaled to the inlet and a flow rate is proportional to achieve a physiological wall shear stress (WSS). Traction-free boundary conditions are applied to the outlets. The time steps are $0.0001 \mathrm{~s}$ and transient analysis with an initial value specification is performed.

\section{Rupture Status}

A lot of CFD studies were reported regarding the rupture status of cerebral aneurysms. Compared with unruptured aneurysms, ruptured aneurysms had significant characteristics such as low WSS [12-15], high oscillatory shear index (OSI) [12, 14], low aneurysm formation indicator (AFI) [12], prolonged relative residence time (RRT) [16], complex 
flow pattern, unstable flow pattern [17], and high oscillatory velocity index [18]. Among these hemodynamic parameters, low magnitude of WSS is the most noticeable hemodynamic characteristic associated the rupture status. Since the magnitude of WSS was quantified as time-averaged value, spatial minimum and maximum values on the dome, normalized WSS and low shear area ratio, we should recognize that the distribution of low WSS would be an unchanged observation. However, comparison of the magnitude of WSS in clinical practice should be carried out as an optimal quantification. For instance, time-averaged WSS would be allowed to investigate the rupture status of multiple cerebral aneurysms in a patient with subarachnoid hemorrhage. In particular, mirror aneurysms are a useful disease model to predict the rupture site of an aneurysm. On the other hand, normalized WSS would be recommended for measuring WSS of aneurysms at different locations.

\section{Hyperplastic Remodeling of Aneurysm Wall}

$\mathrm{Ku}$ described OSI that was a hemodynamic parameter to evaluate fluctuation of WSS vectors in 1985 [19]. The studies using the pulsatile flow data in a Plexiglas model and intimal plaque thickness in five human carotid bifurcations revealed that oscillations in the direction of wall shear may enhance atherogenesis. Aside from OSI, RRT and AFI can also evaluate oscillation of WSS vectors. These hemodynamic parameters were examined regarding hyperplastic remodeling of aneurysm wall. Since these hemodynamic parameters showed similar distribution to high oscillatory WSS vector (Fig. 1), we can use any of these variables as the preoperative predictor of thick aneurysm wall. In addition, we should recognize that a high OSI region corresponds to a low WSS region.

The prediction of hyperplastic remodeling lesions using CFD $[6,11,16]$ would contribute to avoiding intraoperative risks such as inadequate temporary clipping and obstruction of small branches (Fig. 2).

\section{Recurrence of Coiled Aneurysms}

Coil embolization of cerebral aneurysms is widely used; however, recanalization and re-treatment occur more often compared with surgical clipping. Several risk factors for recanalization and re-treatment have been reported, such as a large aneurysm, wide neck width, minor recurrence on cere- bral angiogram early after coil embolization, and lower packing density.

A number of authors reported hemodynamic risk factors associated with coiled aneurysms. High WSS observed near the remnant neck of partially coiled aneurysms are more likely to have recanalization [20]. However, since the geometry of neck remnant is obtained only after coiling, it is impossible to predict the recurrence risk as presurgical decision-making based on this method. In a clinical setting, it is desirable that hemodynamic evaluation using presurgical geometry models can predict recanalization of coiled aneurysms. Sugiyama et al. demonstrated the correlations between the hemodynamics before coil embolization and the outcomes after treatment for basilar tip aneurysms [21]. In their study, aneurysmal inflow rate coefficient (AIRC) was calculated by the following equation:

$$
\operatorname{AIRC}=\frac{Q_{\mathrm{a}}}{Q_{\mathrm{b}}}
$$

where $Q_{\mathrm{a}}$ and $Q_{\mathrm{b}}$ were the aneurysmal inflow rate and the basilar artery flow rate, respectively.

In 57 basilar tip aneurysms, AIRC was significantly higher in the recanalized group and correlated to the types of basilar bifurcation configuration. Although it was sensible to make a decision for coil embolization based on these findings, packing density should be considered simultaneously. Therefore, CFD using porous media modeling was developed to predict recurrence of coil embolization. Umeda et al. calculated residual flow volume (RFV) to quantify the residual aneurysm volume after simulated coiling, which has a mean fluid domain above $1.0 \mathrm{~cm} / \mathrm{s}$ [22]. In 37 unruptured cerebral aneurysms, the recurrence group had significantly larger RFV than the stable group. Receiver-operating characteristic (ROC) curve analyses showed that the cut-off value of RFV was $20.4 \mathrm{~mm}^{3}$ and that the area under the ROC curve was 0.86 . Although this study was retrospective, these findings could be applied to indicate a target packing density. In addition, CFD using double porous media modeling was developed to simulate stentassisted coiling (Fig. 3) [23]. Since these porous media modeling have discrepancies between actual distribution of placed coil and expanded strut in the aneurysm, large-scale clinical studies are required to confirm the accuracy of the prediction for recurrence of coiled aneurysms. 

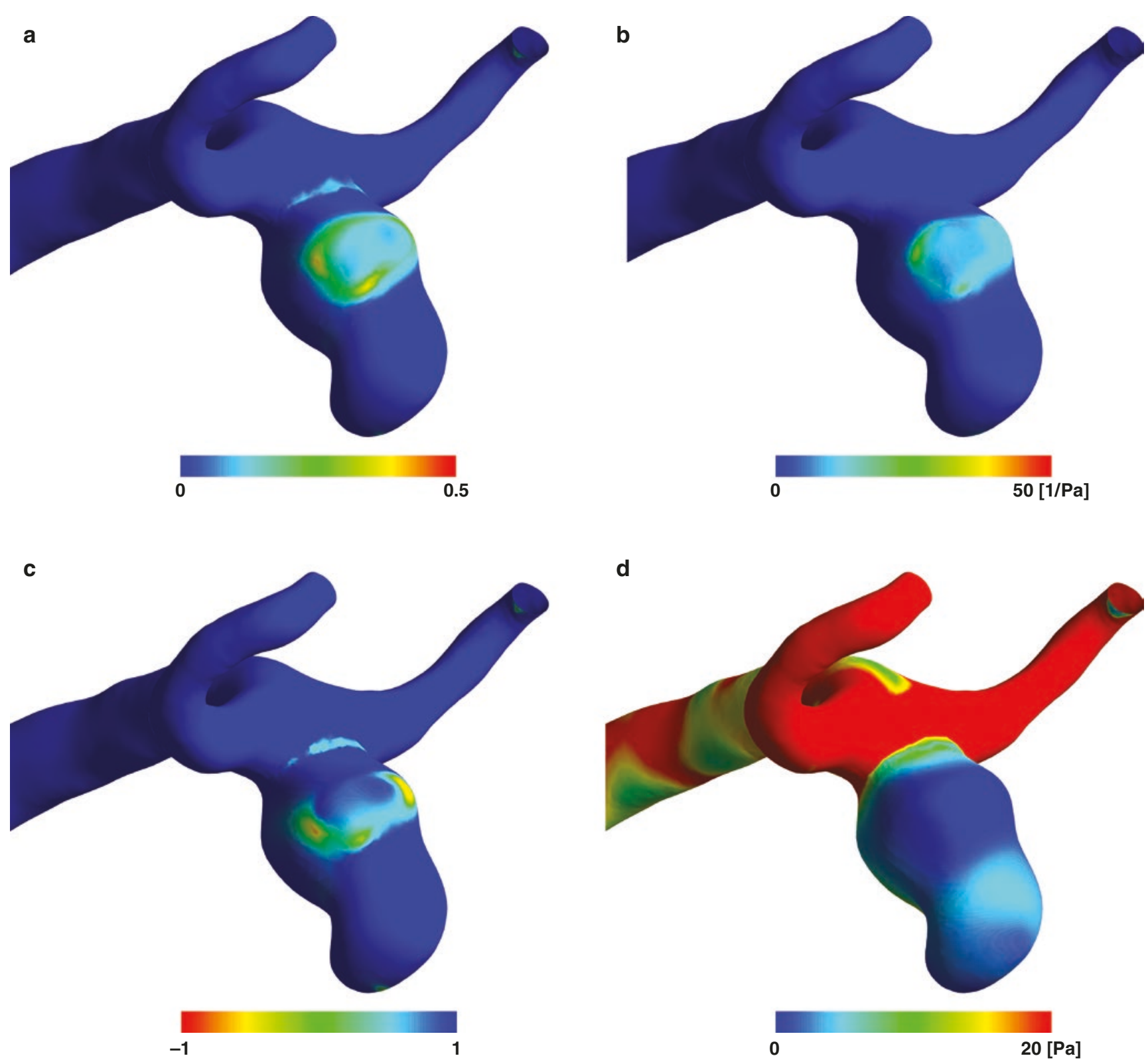

Fig. 1 Comparison of hemodynamic parameters to evaluate the fluctuation of WSS vector in a patient of ruptured middle cerebral artery aneurysm: (a) visualization of OSI, showing high OSI near the neck; (b) visualization of RRT; (c) visualization of AFI, in which low AFI has

similar distribution to prolonged RRT and low WSS; (d) visualization of WSS, in which high OSI, prolonged RRT and low AFI regions are depicted in the low WSS area 
a
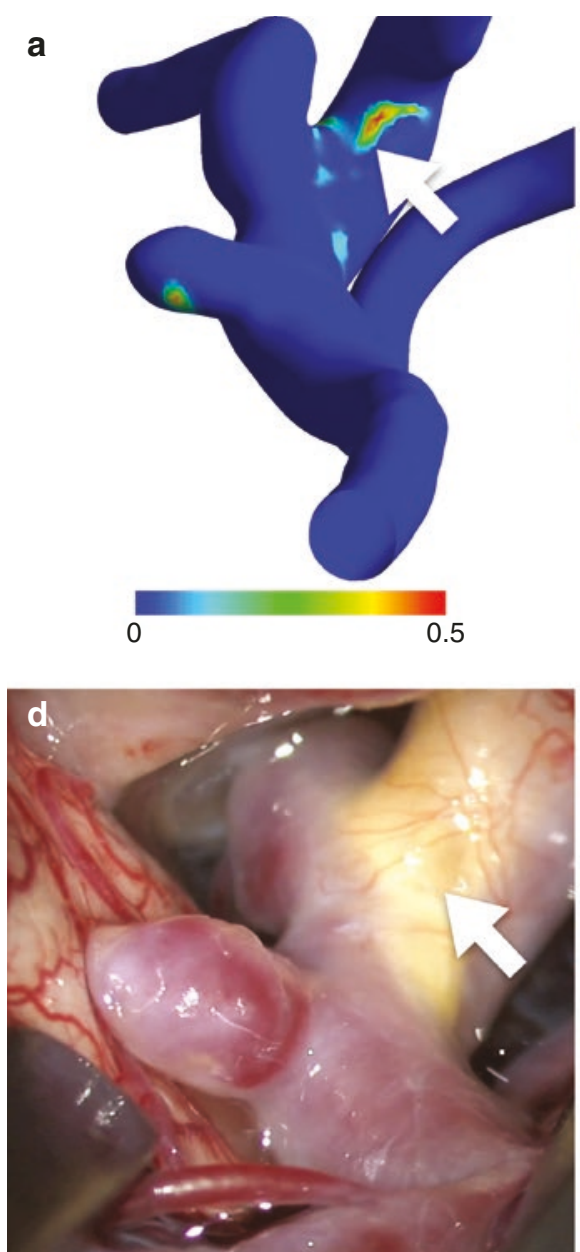

b

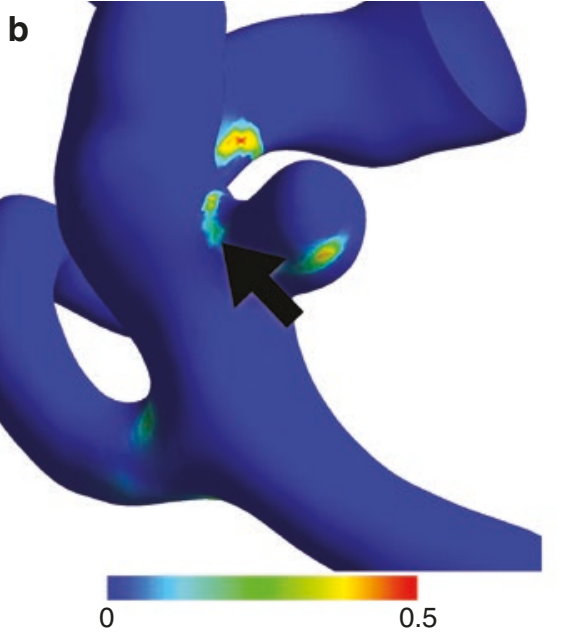

C

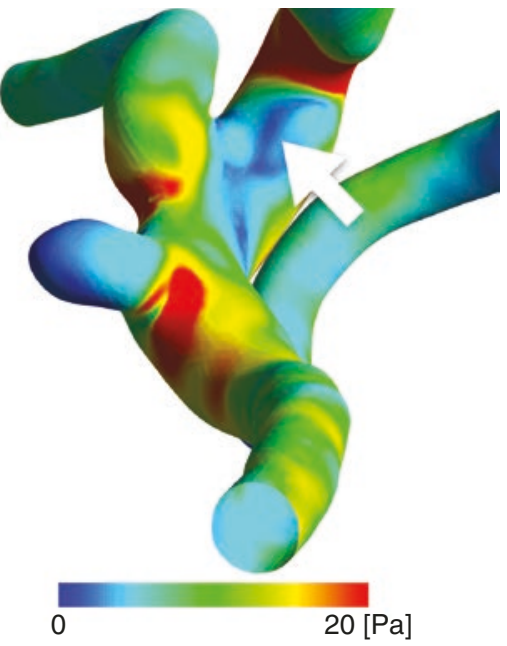

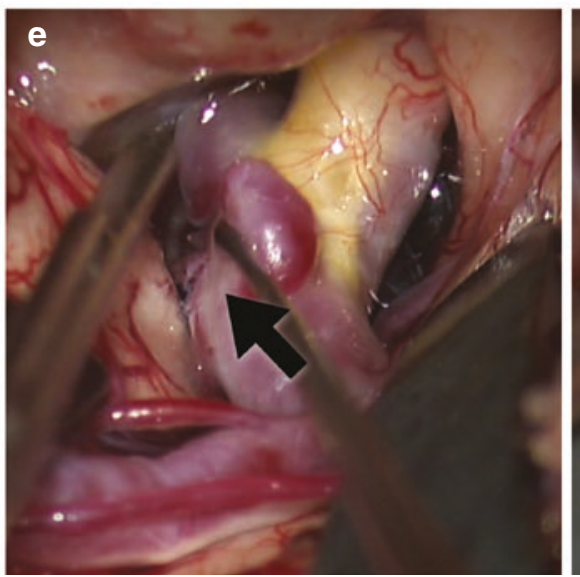

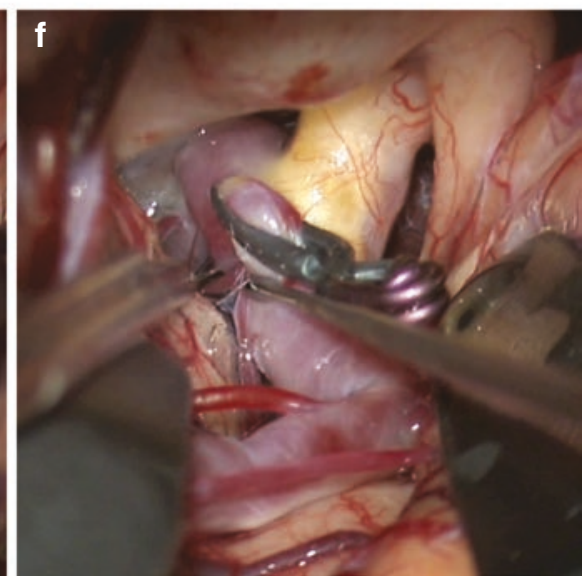

$(\mathbf{d}, \mathbf{e})$ intraoperative photography, demonstrating atherosclerotic lesions of the parent artery (white arrow) and at the backside of the aneurysm neck (black arrow), respectively, which correspond with high OSI regions; (f) aneurysm clip is applied with an intended space to keep blood flow of the anterior choroidal artery 

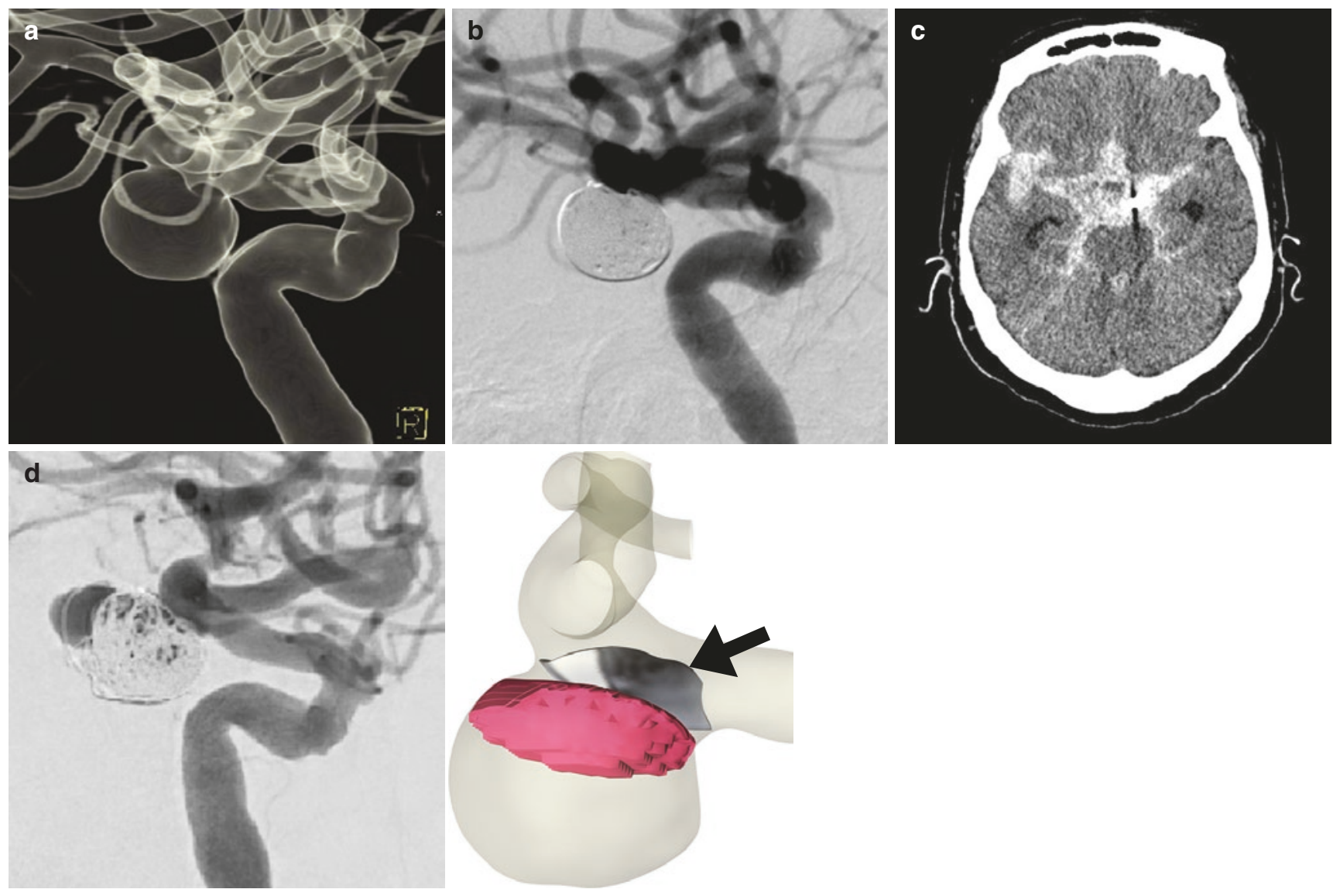

Fig. 3 Seventy-nine-year-old woman with left internal carotid arteryposterior communicating artery bifurcation aneurysm: (a) 3D surface rendering image of rotational angiography; (b) angiography after stentassisted coiling of the aneurysm with a packing density of $35.9 \%$; (c) head CT revealing subarachnoid hemorrhage 19 months after the coiling; (d) left internal carotid artery angiography revealing the recanalization of the coiled aneurysm; (e) retrospective CFD findings using

double porous media setting, one of which is a porous media setting for the coiled aneurysm and another of which is that for an intracranial stent (arrow), to evaluate the hemodynamic changes of stent-assisted coiled aneurysm. Residual flow volume (pink domain) is $62.3 \mathrm{~mm}^{3}$, which is larger than the cut-off value to predict the recurrence of coiled aneurysms 


\section{Conclusions}

This review describes the practical application of CFD to treatment planning of cerebral aneurysms. Several hemodynamic parameters have valuable aspects not only in an endovascular treatment but also in a direct clipping. Although prospective trials are needed to evaluate the rupture risk of unruptured cerebral aneurysms determined using CFD, recent knowledge of hemodynamics of cerebral aneurysms would enhance the decision-making ability and precision in several clinical settings.

Conflict of Interest The authors declare that they have no conflict of interest.

\section{References}

1. Steinman DA, Milner JS, Norley CJ, Lownie SP, Holdsworth DW (2003) Image-based computational simulation of flow dynamics in a giant intracranial aneurysm. AJNR Am J Neuroradiol 24:559-566

2. Fukazawa K, Ishida F, Umeda Y, Miura Y, Shimosaka S, Matsushima S, Taki W, Suzuki H (2015) Using computational fluid dynamics analysis to characterize local hemodynamic features of middle cerebral artery aneurysm rupture points. World Neurosurg 83:80-86

3. Kulcsa Z, Marosfo M, Paa G (2011) Hemodynamics of cerebral aneurysm initiation: the role of wall shear stress and spatial wall shear stress gradient. AJNR Am J Neuroradiol 32:587-594

4. Mantha A, Karmonik C, Benndorf G, Strother C, Metcalfe R (2006) Hemodynamics in a cerebral artery before and after the formation of an aneurysm. AJNR Am J Neuroradiol 27:1113-1118

5. Meng H, Wang Z, Hoi Y, Gao L, Metaxa E, Swartz DD, Kolega J (2007) Complex hemodynamics at the apex of an arterial bifurcation induces vascular remodeling resembling cerebral aneurysm initiation. Stroke 38:1924-1931

6. Omodaka S, Sugiyama SI, Inoue T, Funamoto K, Fujimura M, Shimizu H, Hayase T, Takahashi A, Tominaga T (2012) Local hemodynamics at the rupture point of cerebral aneurysms determined by computational fluid dynamics analysis. Cerebrovasc Dis 34:121-129

7. Stress S, Boussel L, Rayz V et al (2008) Aneurysm growth occurs at region of low wall shear stress: patient-specific correlation of hemodynamics and growth in a longitudinal study. Stroke 39:2997-3002

8. Takao H, Murayama Y, Otsuka S, Qian Y, Mohamed A, Masuda S, Yamamoto M, Abe T (2012) Hemodynamic differences between unruptured and ruptured intracranial aneurysms during observation. Stroke 43:1436-1439

9. Tateshima S, Villablanca JP, Vin F (2011) Wall shear stress distribution inside growing cerebral aneurysm. AJNR Am J Neuroradiol 32:1732-1739
10. Tsuji M, Ishikawa T, Ishida F, Furukawa K, Miura Y, Sano T, Tanemura H, Umeda Y, Shimosaka S, Suzuki H (2017) Stagnation and complex flow in ruptured cerebral aneurysms: a possible association with hemostatic pattern. J Neurosurg 126:1566-1572

11. Furukawa K, Ishida F, Tsuji M et al (2018) Hemodynamic characteristics of hyperplastic remodeling lesions in cerebral aneurysms. PLoS One 13:e0191287

12. Miura Y, Ishida F, Umeda Y, Tanemura H, Suzuki H, Matsushima S, Shimosaka S, Taki W (2013) Low wall shear stress is independently associated with the rupture status of middle cerebral artery aneurysms. Stroke 44:519-521

13. Lu G, Huang L, Zhang XL, Wang SZ, Hong Y, Hu Z, Geng DY (2011) Influence of hemodynamic factors on rupture of intracranial aneurysms: patient-specific 3D mirror aneurysms model computational fluid dynamics simulation. Am J Neuroradiol 32:1255-1261

14. Xiang J, Natarajan SK, Tremmel M, Ma D, Mocco J, Hopkins LN, Siddiqui AH, Levy EI, Meng H (2011) Hemodynamic-morphologic discriminants for intracranial aneurysm rupture. Stroke 42:144-152

15. Xu J, Yu Y, Wu X, Wu Y, Jiang C, Wang S, Huang Q, Liu J (2013) Morphological and hemodynamic analysis of mirror posterior communicating artery aneurysms. PLoS One 8:e55413

16. Sugiyama S, Niizuma K, Nakayama T, Shimizu H, Endo H, Inoue T, Fujimura M, Ohta M, Takahashi A, Tominaga T (2013) Relative residence time prolongation in intracranial aneurysms: a possible association with atherosclerosis. Neurosurgery 73:767-776

17. Cebral JR, Mut F, Weir J, Putman C (2011) Association of hemodynamic characteristics and cerebral aneurysm rupture. AJNR Am J Neuroradiol 32:264-270

18. Sano T, Ishida F, Tsuji M, Furukawa K, Shimosaka S, Suzuki H (2017) Hemodynamic differences between ruptured and unruptured cerebral aneurysms simultaneously existing in the same location: 2 case reports and proposal of a novel parameter oscillatory velocity index. World Neurosurg 98:868.e5-868.e10

19. Ku DN, Giddens DP, Zarins CK, Glagov S (1985) Pulsatile flow and atherosclerosis in the human carotid bifurcation. Positive correlation between plaque location and low oscillating shear stress. Arterioscler Thromb Vasc Biol 5:293-302

20. Luo B, Yang X, Wang S et al (2011) High shear stress and flow velocity in partially occluded aneurysms prone to recanalization. Stroke 42:745-753

21. Sugiyama S, Niizuma K, Sato K, Rashad S, Kohama M, Endo H, Endo T, Matsumoto Y, Ohta M, Tominaga T (2016) Blood flow into basilar tip aneurysms: a predictor for recanalization after coil embolization. Stroke 47:2541-2547

22. Umeda Y, Ishida F, Tsuji M, Furukawa K, Shiba M, Yasuda R, Toma N, Sakaida H, Suzuki H (2017) Computational fluid dynamics (CFD) using porous media modeling predicts recurrence after coiling of cerebral aneurysms. PLoS One 12:e0190222

23. Tsuji M, Ishida F, Kishimoto T, Furukawa K, Miura Y, Shiba M (2016) Computational fluid dynamics using double porous media modeling to simulate stent-assisted coiling of cerebral aneurysm. Proc Neurosci 1:144-147

Open Access This chapter is licensed under the terms of the Creative Commons Attribution 4.0 International License (http://creativecommons. org/licenses/by/4.0/), which permits use, sharing, adaptation, distribution and reproduction in any medium or format, as long as you give appropriate credit to the original author(s) and the source, provide a link to the Creative Commons license and indicate if changes were made.

The images or other third party material in this chapter are included in the chapter's Creative Commons license, unless indicated otherwise in a credit line to the material. If material is not included in the chapter's Creative Commons license and your intended use is not permitted by statutory regulation or exceeds the permitted use, you will need to obtain permission directly from the copyright holder. 